\title{
A variety of designs construction and mounting
}

\author{
Tamara Danchenko ${ }^{1, *}$, Anatoly Lastovka ${ }^{1}$, Sergey Amelchugov ${ }^{1}$, Nadezhda $_{\text {Klinduh }}{ }^{1}$, and \\ Maria Berseneva ${ }^{1}$ \\ ${ }^{1}$ Siberian Federal University, 660041, Krasnoyarsk Territory, Krasnoyarsk city, 79 Svobodny \\ Avenue, Russia
}

\begin{abstract}
Abstract in the article the main types of building structures are considered, which are distinguished by the type of material. For the purpose of studying, each type has brief information including its advantages and disadvantages in comparison with others. In the section reinforced concrete structures, the authors characterize this material from three sides - this is the method of manufacture, the type of concrete and its stressed state. As a result, it was found that when choosing a foundation, special attention is paid to: bearing capacity, type of building being built, soil characteristics. In addition to the above, it can be added that weight reduction, cost reduction and material consumption in reinforced concrete structures are possible through the use of high-strength concrete and reinforcement. Metal structures are the most popular building material. The possibilities of this material are very diverse: building designs, designs specifically for certain seismic and climatic conditions, and high decorative properties. Due to its strength and rigidity, buildings can withstand hurricane gusts of wind and earthquakes. In the manufacture of structures in the factory and during installation, steel is subjected to various technological operations: welding, cutting, machining. It was found that in this case the steel does not collapse, it retains the microstructure and mechanical properties. Finally, steel should not have a significant cost of manufacturing structures from it. Turning to the section of wooden structures, the authors list the main advantages - it is comfortable and environmentally friendly and material.
\end{abstract}

\section{Introduction}

It would seem as if everything is well-known about building structures. Basically, one needs to be aware of categorizing them into functional purposes of the load-bearing and enclosing constructions, as well as to bear in mind that this fact is largely a conditional concept. But as for students of construction industry, especially Bachelors of junior courses, then they might hear these truths for the first time. Structures such as arches, trusses serve mainly the load-bearing or supporting purposes, but there are structures that combine enclosing and bearing functions, these include wall panels, cladding panels, arches, and many others. In turn, the load-bearing structures are divided into flat (beams, trusses, frames) and spatial (domes, shells, arches). The preference is usually given to spatial, as

* Corresponding author: danchenko_53@inbox.ru 
they are characterized by a more favorable distribution of loads and lower material consumption. But the topic of the following paper does not begin with these complex concepts. We would better start with the fact that the main types of structures are distinguished according to the type of material and they are mainly divided into the following types: reinforced concrete structures and products, steel structures, wooden, stone, reinforced stone; plastic and complex (a combination of several types of materials). Let us now look at these in more details.

\section{Reinforced ferroconcrete structures}

In modern construction ferroconcrete structures (hereinafter abbreviated as FCS) are classified according to the method of execution into the following: monolithic cast-in-situ structures, prefabricated and precast and cast-in-situ construction. According to the type of concrete they vary from heavy, light, cellular to heat-resistant and other concrete; structures. As for the type of stress condition FCS are classified as ordinary or prestressed.

Cast-in-situ structures, precast and cast-in-situ structures include foundations, which is the basis of all residential, public, industrial buildings and many engineering structures [1]. Foundations and their varieties are selected depending on the type of structure being built on them. Each type of basement may have not only constructive features, but also its own applicability. Factors which influence the choice of this or that foundation include: soil characteristics, namely its bearing capacity. For instance, freezing depth largely depends on the type of soil, as the more its saturation with water, the stronger the heaving and rebound. The type of structure being built is its weight (walls, ceilings), static dynamic loads, other features, this is the presence of a basement, a cellar. Groundwater's - the depth of the foundation depends on their level (which is commonly determined by engineering and geological research, such as well drilling). The main advantages of reinforced ferroconcrete structures are high strength, durability, fire resistance, ease of shaping. In addition to the above, it should be noted that in the construction of buildings and structures operated at high and low temperatures, as well as in chemically aggressive environments, special types of concrete and reinforced ferroconcrete are used. Weight reduction, cost reduction and material consumption in reinforced ferroconcrete structures are possible in case highstrength concrete and reinforcement are applied.

The building must be safe at all stages of its life cycle, including the probability of fire. The influence of the service life in an aggressive environment on the strength properties of concrete is calculated by multiplying by the coefficient of reduced strength of materials, taking into account the period and degree of aggressive effect. The bearing capacity of reinforced ferroconcrete structures under fire exposure is largely dependent on changes in the strength and deformability of concrete and reinforcement with increasing temperature. The fire resistance of a reinforced ferroconcrete structure is achieved as a result of the loss of its bearing capacity (collapse) due to a decrease in the strength (thermal creep) of reinforcing steel and concrete when being heated [2], or due to the loss (deprivation) of heat-insulating ability (when heating the structure above the maximum permissible temperature), as well as as a result of loss (deprivation) of continuity (integrity, uniformity) of the building envelope or filler structure. The fire resistance of a reinforced ferroconcrete when applied in the inner non-bearing wall and partition is determined by the loss of heatinsulating ability or by the loss of uniformity. This rate depends on the type of concrete (heavy, light, cellular) and the thickness of the structure.

Prefabricated structures have significant advantages over monolithic, due to the fact that they create wide opportunities for industrialization of construction [3, 4]. Large-sized reinforced ferroconcrete structures allow companies to transfer a huge amount of construction of buildings and utilities from the construction site to the plant with a highly 
organized production process. In order to understand the ferroconcrete structures drawings, students have to perform the following assignment. Firstly, the task checks the student's ability to read the drawings of reinforced concrete structures, to distinguish the formwork drawing from the reinforcement (Fig. 1 entryway to the building). It is only required to prepare specification of the reinforcing carcass. Secondly, a student should write down the length of the reinforcing bars on the drawing, calculate their number and put down their mass. Finally, the task includes calculating the mass of the reinforcing carcass and presenting it in the specification.

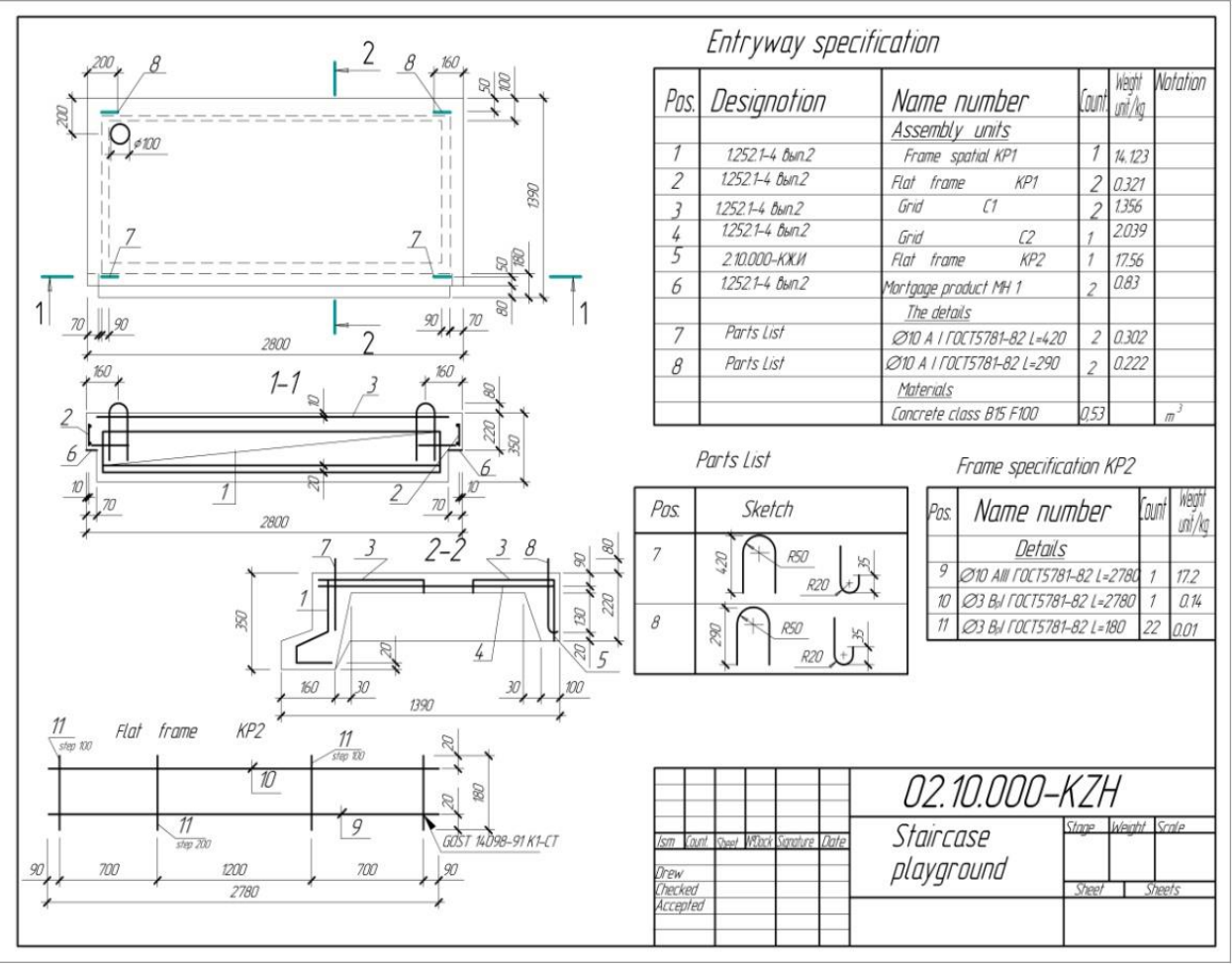

Fig. 1. Drawing of the landing. Concrete waterproof material class B15 F100 W4 (compiled by the author).

\section{Metal structures}

One of the most popular building materials is metal, as well as a variety of metal structures, which form the basis for modern construction. The advantage of metal structures is that they are relatively easy to manufacture, as well as to mass produce for individual use. Other benefits include spatial strength, stiffness [5], fast installation and deinstallation. Resistance of steel to termites, rodents, mold and other factors is also a big plus. In addition, the metal does not concentrate high humidity. There is also uniformity of material as almost any metalwork is produced at the enterprises in series, so there is surely a very high degree of repeatability of products. Metals do not burn, although - during a fire, the main parameter for steel is the yield strength, as fire safety standards require the calculation of the bending moment of the structure, $[6,7]$ which was thermally exposed to Mp according to the following formula: $\mathrm{Mp}=\mathrm{Ry} * \mathrm{Wh}$, where: $\mathrm{Ry}$ is the limit yield at temperature $\mathrm{t}, \mathrm{MPa}, \mathrm{Wh}$ is the moment of resistance of the cross section, MPa. 
It is possible to develop a building design specifically for some extreme seismic and climatic conditions. Buildings can be constructed in such a way as to withstand gusts of wind during hurricanes and even earthquakes of a certain strength without violating the integrity of the building. Moreover, metal structures are famous for their high decorative properties (see Fig. 2).

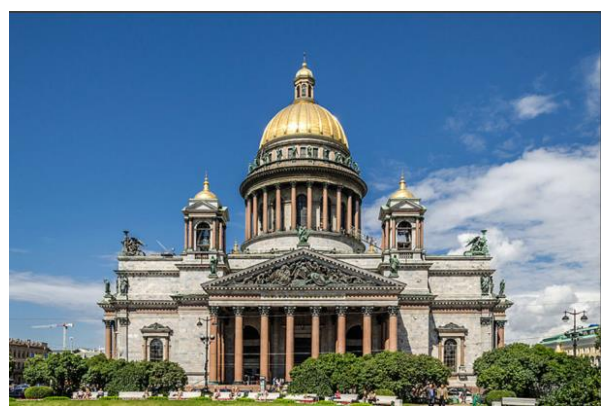

Fig. 2. Dome of St. Isaac's Cathedral in St. Petersburg (developed by www.booking.com).

Dome of St. Isaac's Cathedral in St. Petersburg, Mary-Ex skyscraper (Fig. 3).

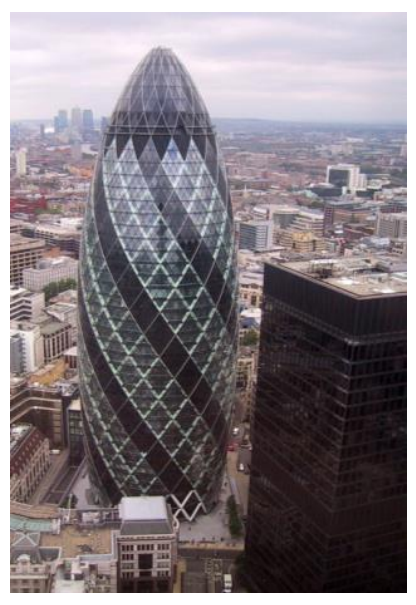

Fig. 3 Mary-Ex Skyscraper

The areas of application of metal in modern construction are impressively huge. Part of the produced steel is spent on manufacturing metal structures from which road anrailway bridges are constructed, frames of industrial and civil buildings (Fig. 4), masts and towers of antenna devices, power transmissions (Fig. 5), gas storage tanks for storing oil, oil products and gas, and much more. Thanks to the joint efforts of metallurgy workers, metal experts and welding specialists, there have been improvements in existing still grades and new steel grades and types of rolled products have been introduced. The dimensions of the cross sections of the elements of metal structures and their mass are determined by a calculation that takes into account the strength properties of the material - yield strength and tensile strength. Increased strength of steel allows to enhance the design load, which makes it possible for the further development of new structural and architectural forms. In the manufacture of structures in the factory and during installation, steel is subjected to various technological operations: welding, cutting by fire and mechanical methods, machining, dressing, bending and rolling. And while the steel is not destroyed, it retains its microstructure and mechanical properties. Finally, cost of manufacturing structures from steel should be reasonable. 


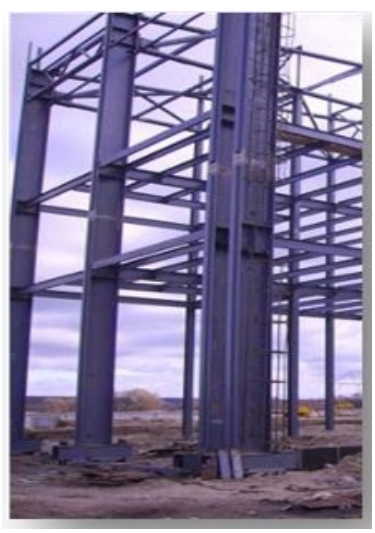

Fig. 4 Metal structures of the columns.

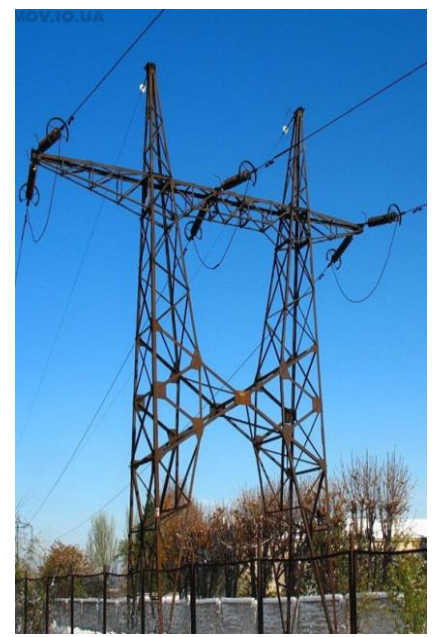

Fig. 5 Steel transmission line supports (developed by $\underline{\text { ru.depositphotos.com/so) }}$

When designing building steel structures the minimum required number of different profiles is applied. Metal for general purposes with a variety of power effects of tensile, compression and bending is commonly used. The group includes (Fig. 6),

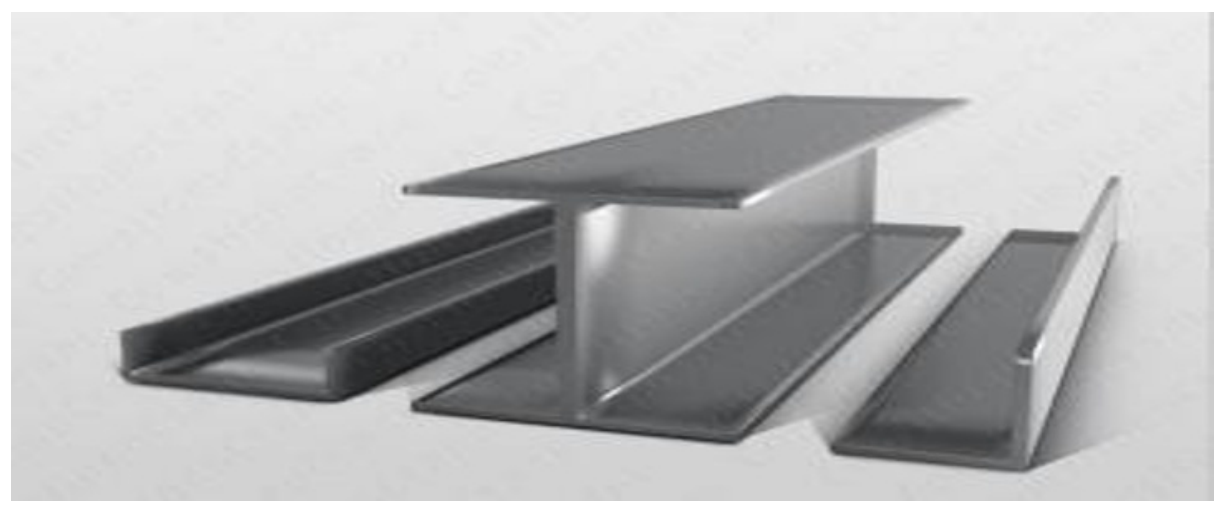

Fig. 6 Steel profile (developed by fkmgroup.ru/fasonnyj-prokat.html) 
double-T-irons, beams, channels, angles, equilateral and unequal tees, square tubes, rectangular and circular tubes, sheet metal, steel ropes, etc.

When calculating fire resistance of metal structures, it is taken into account that the mechanical properties of metals are determined only by their temperature and are independent of the mode of heating, loading and deformation. The temperature is distributed evenly over the cross-section of structural elements, the diagram of metal deformation at high temperatures is similar to the diagram under normal conditions, and the fracture time of a metal structure is determined by the time of their heating to a critical temperature.

(developed http://y-dom.com.ua/i9910.html)

Wooden structures

This is one of the oldest types of building structures (Fig. 7).

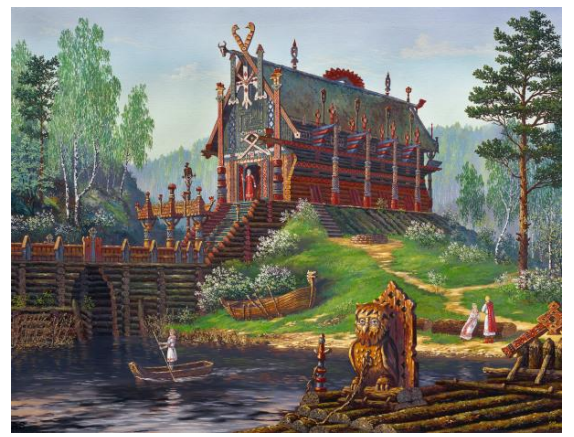

Fig. 7. A wooden house (developed by dis.academic.ru).

The main advantages include: the ability to use local materials, low bulk volume weight, transportability, ease of processing, low thermal conductivity. In modern construction two types of construction are mainly used. The first type is manufactured without the use of glue, with elements from beams and boards and pliable joints on pins and nails $[8,9]$. The second is glued, incorporating factory-made wooden glued elements. The most important advantages of glued constructions are the production of monolithic elements of almost any size and cross-sectional shape, which have increased bearing capacity, durability and fire resistance; high-performance when using this type of material (mainly small and mixed lumber).

Timber and wood products used in construction are commonly divided into the following types: round timber, sawn timber and wood products. The round timber represents (Fig. 8 depicts a house made of round cedar)

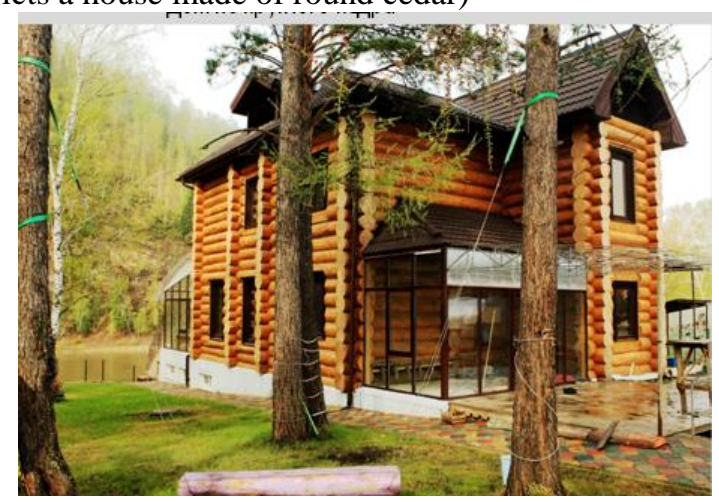

Fig. 8 House of logs. 
trunks, peeled of bark and twigs. Sawn timber or two-edged timber represents lumber which is sawn from two sides, or timber sawn from four sides (Fig. 9, the cedar house).

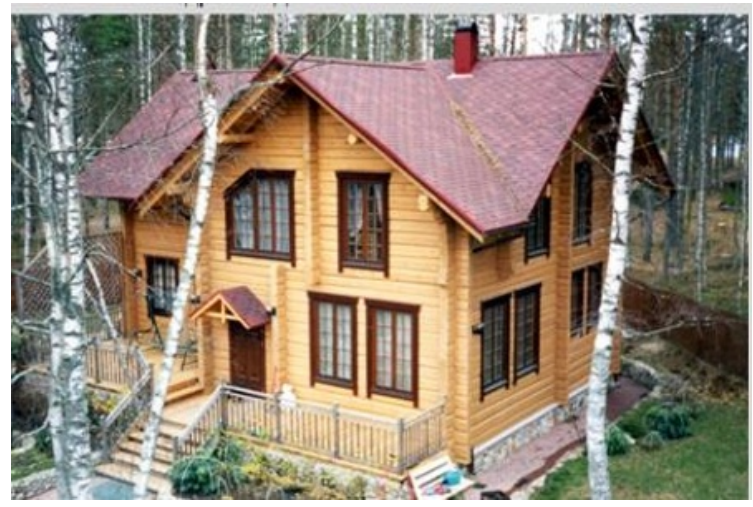

Fig. 9 The House of the profiled bars (photo by the author).

Timber products include tongue-and-groove boards, plinths, plat bands, parquet, window and door blocks, etc.

In construction timber is a recognized environmentally friendly and comfortable material. The aesthetics of $\log$ connections, intersections and cross-shaped structures seem really pleasing to visual perception. Coniferous species are most widely used in modern construction (due to the greater prevalence and better quality of wood). Deciduous species aspen, birch, alder, linden and poplar are mainly used for the construction of temporary buildings, fences. They are also applied when manufacturing doors, platbands, partitions or formwork for concrete work. In Russia, when operating wooden buildings, as well as in other countries, the conditions for saving energy consumption are met. Autonomous heating systems, thanks to which you can reduce energy consumption by $20-30 \%$. The conditions for saving are not at all complicated as walls and the floor in the house can withstand dark colors, which allows it to absorb thermal energy as much as possible. Structural elements of the building, cornices, peaks, roofs are built so that in the summer season they protect the house from overheating, and in winter as much sunlight as possible gets into the house. When designing wooden buildings, everything is thought out to the smallest detail. To increase the amount of incoming solar energy, large windows are made on the south side of the building, and the facade on the north side is blind or with small windows.

In the project "Coordination of high-latitude construction" of teachers of the Engineering and Construction Institute of Siberian Federal University, variants of wooden construction houses for the Arctic were developed [10]. Scientists have come to the conclusion that it is necessary to choose the optimal shape of the building, which will not be protected from the effects of strong wind, snow, snowstorm due to aerodynamic forms. Houses that consisted of combinations of domed forms of wooden structures were designed (Fig. 10). The building is in the form of a lens of different radii or in the form of a sphere: a spaceship-like house.

External type- self-supporting mesh bent glued wood panels. The outer side is a composite materials, the inner is a 2-layer drywall. Panel thickness and insulation are selected according to operating conditions. Fire Resistance REI-30. Fire hazard class K-0. Some fears are associated with wooden structures as wood burns very well. Various approaches are offered to prevent the spread of fire across wooden structures. Passive methods of protection include fire-resistant wood impregnation, as well as the use of noncombustible materials (like mineral wool, plaster) over window openings, which prevent the spread of fire to the upper floors. Active methods of protecting a wooden building 
include the use of water extinguishing systems. The best solution is achieved at the design stage through the use of special solutions and new materials. When constructing a buildings, the project involves the use of glued wood. Glued wood consists of several layers - lamellas, where ordinary glue is used. But if gluing is done with smart glue, then it will protect wooden structures from fire and in case of fire only the first lamella will be charred.

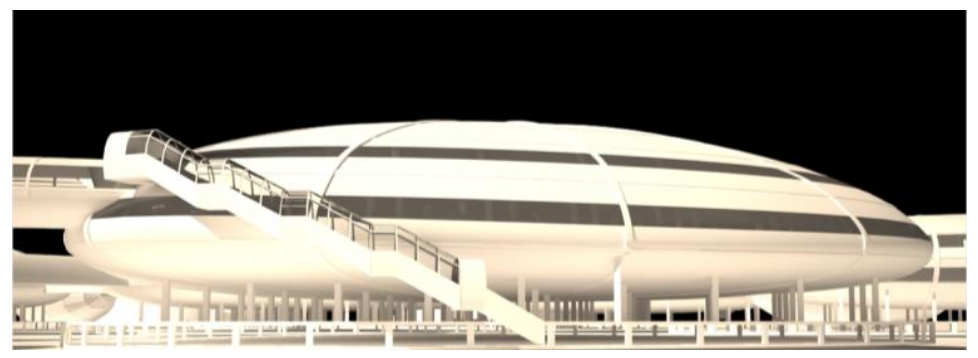

Fig. 10 Tenement house (photo by the author).

There are two options for updating the housing stock of Arctic settlements: restoration of existing buildings and construction of new ones. In this regard, the task arose - to use light materials, for example, engineered wood, which is five times lighter than reinforced ferroconcrete, when designing buildings. Firstly, t has good thermal and mechanical properties and secondly, it is comfortable, environmentally friendly way of housing.

\section{Stone structures and reinforced masonry structures}

Stone structures are masonry made of artificial or natural stones, combined into a single monolithic material using mortar. A little bit of history - the first bridges began to be built in the era of slave society. Great successes in stone bridge building were achieved by the ancient Romans (Fig. 11), who used vaulted structures as supports and used cement, a secret that was lost in the Middle Ages. Many outstanding monuments of stone architecture have survived to this day.

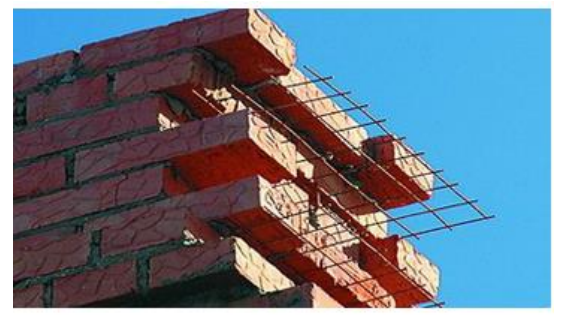

Fig. 11. Ancient Roman bridge Ponte de Tiberio in Rimini (900igr.net/kartinki).

Stone structures have not lost their significance and are used in all climatic regions. These structures are used as load-bearing structures for eccentrically compressed elements with a limited eccentricity of the application of external forces (walls, pilasters, poles, foundations, chimneys, water towers, retaining walls, towers, bridge supports, etc.). Stone structures are not perfect enough for buildings and structures subject to dynamic effects, for construction in seismic areas, under the influence of an aggressive environment, systematic technological temperatures above $100^{\circ} \mathrm{C}$, in permafrost zones. Along with artificial stone materials (bricks, hollow ceramic or concrete stones, solid stones and blocks of light, polymer concrete and cellular concrete), it is recommended to use natural stone materials (limestone, tuff), sawn from rock masses. Such a type of reinforced masonry structure is 
also called armor-stone, due to the reinforcement of stone structures with steel wire and mesh (Fig. 12).

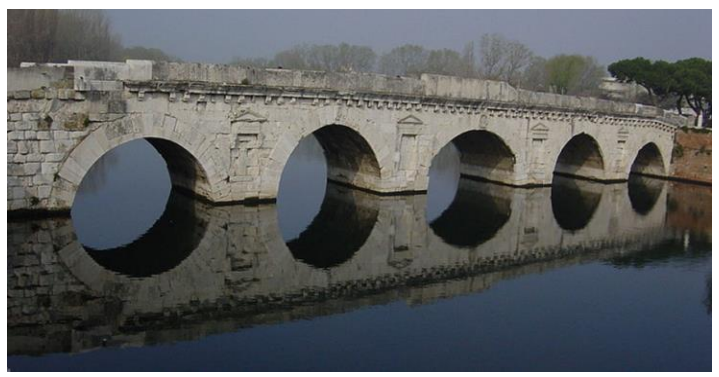

Fig. 12. Installation of stone and reinforced stone structures (developed b2b.by/montazh-kamennyxi).

The use of reinforced armored masonry can significantly expand the scope of stone materials in building structures $[11,12]$. The advantage of stone structures is fire resistance, durability, good heat and sound insulation and low maintenance. The disadvantages include a large net weight and significant cost of manual labor during construction.

When designing stone and reinforced masonry structures it is necessary to apply constructive solutions, products and materials that provide the required bearing capacity and thermal characteristics of structures. It should be guided by the provisions of State Standard GOST 54257-2010 "Reliability of building structures and foundations". As for reinforcing stone structures, they must be used in accordance with such standards as SNiP 52-01-2003. (SNiP 52-01-2003 Concrete and reinforced ferroconcrete structures. General provisions. Since 01.07.2015 not applicable - updated version of SP 63.13330.2012 Concrete and reinforced ferroconcrete structures. General provisions).

\section{Plastic constructions}

Plastic constructions begin their history in 1872, when the first celluloid, a rigid transparent material, was obtained. For the first time, plastics for building structures began to be used abroad in 1956-1957, when experimental residential buildings were created in France (from polystyrene, vinyl plastic, fiberglass). The first building in Russia with the use of translucent polyester fiberglass in the coating was built near Moscow in 1963. Plastics as a structural building material have advantages and disadvantages. Firstly, it is a very lightweight material (low density not exceeding $1500 \mathrm{~kg} / \mathrm{m} 3$ ), so it boasts high strength with low weight, secondly, it is known for resistance to aggressive environment, resistance to decay - these are all the advantages. A significant disadvantage of plastics is its flammability. However, there is every reason to believe that this shortcoming will be overcome in the near future. Other drawbacks may include small stiffness, increased deformability, low surface hardness and moreover the fact that plastic is subject to aging under atmospheric influences [13-15]. Structural plastics include a number of components synthetic resins are one of them. They form the bulk of the materials, and serve as binders similar to cement mortar in concrete. Resins are divided into two main classes:

1. Thermoplastic (polyvinyl chloride, polystyrene, polyethylene, etc.); when heated, they soften and become plastic, and when cooled, they harden again.

They are used to manufacture sheeting, plate stock (such as organic glass, vinyl plastic), glues for bonding, foams, films.

2. Thermosetting (phenol-formaldehyde, polyester, epoxy) resins; they can be transformed from a viscous-flowing to a solid state only once which is in the course of 
curing. This process occurs under the influence of a hardener or during heating. These materials are used to produce fiberglass, foams, adhesives, wood plastics. The technical advantages of plastics include: reduced weight and complexity

of manufacturing building structures; increased industrialization of construction production and increased labor productivity; shortened construction time; reduction of consumption of ferrous and non-ferrous metals, cement and wood. Russian industry produces various types of resins, but only some of them are used in construction, such as polyester resins. This type of resin has a low viscosity, good mechanical properties in the solid state, does not emit volatile products upon solidification. All these materials are commonly used in the manufacture of fiberglass, and are also the basis for adhesives, varnishes, putties.

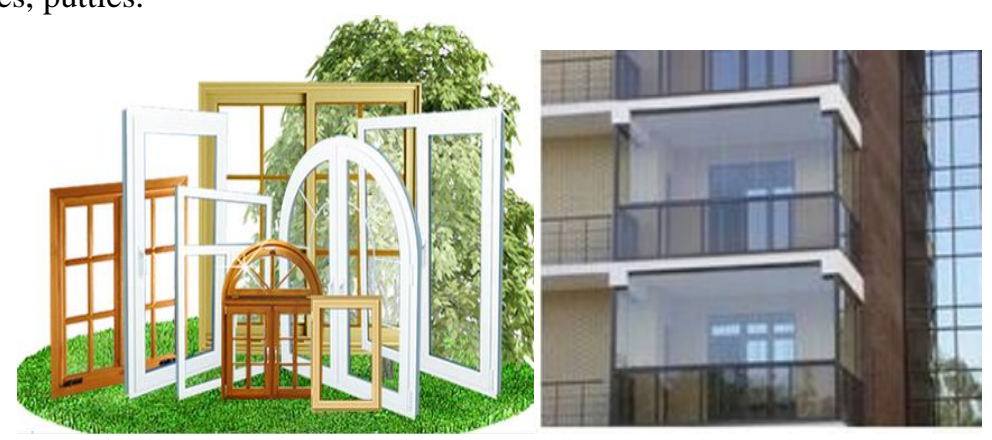

Fig. 13. Plastic design, Windows, doors, balcony railing (developed farpost.ru/service/construction).

The choice of types and brands of plastic products and structures should be made depending on the exploitation and maintenance requirements. These include the estimated service life, manufacturing technology and installation of structures [16]. In this case, it is necessary to take into account the physical and mechanical features of plastics, including hardness, endurance, resistance to high and low temperatures, ultraviolet radiation, and chemical and biological environments.

\section{Integrated (combine several types of materials)}

In order to increase labor productivity and to successfully apply modern achievements, new light materials are used in combination with metal and glass. Such materials include plastics. This is not only a reduction in the weight of the building product, but the possibility to make many decisions in the design. Responsibility for the successful implementation of these achievements lies with builders, chemists, and plastics processors. Intensive research in the field of the use of polymeric materials - which is the search for new types, new technology and new ways of their application - has opened up new opportunities. It has launched the use of plastic products and structures in construction and their rapid implementation in building process, such as latex cement and polymer cement materials, pipelines made of plastics, prefabricated partition structures, organic glass roofing materials, interior decoration and cladding and many other combined materials [17]. The effectiveness of the combination is expressed in improving the use of material resources and equipment, in reducing the cost of production facilities and storage devices. Reasonable combination contributes to the growth of labor productivity and lower production costs. What about the advantages (Fig. 14) of combined houses made of brick and timber? Such designs require special care. Log finishing needs additional processing with a special solution. The advantage and dignity is that the building has a noble appearance, the ability to maintain the optimum temperature in the space of the house in 
any season, the combined development will significantly save the budget on building materials as such a structure can be quickly constructed.

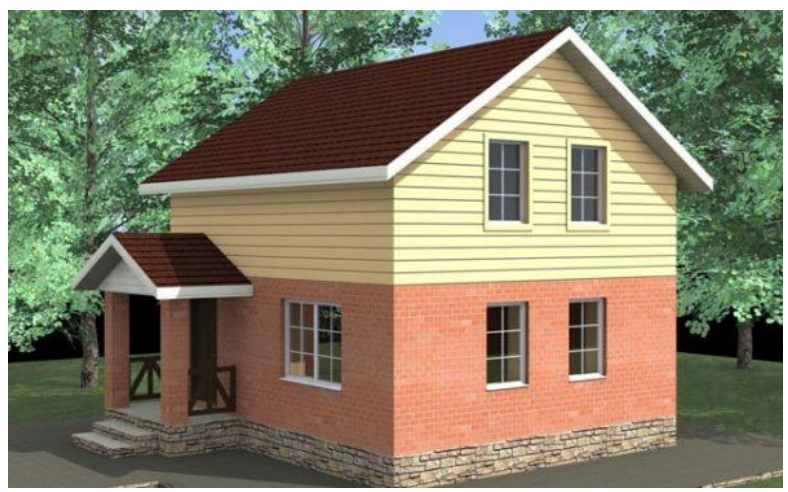

Fig. 14. Combined house (developed by studbooks.net/1774085/ekonomika).

\section{Conclusion}

Designs must meet their intended purpose, be safe, easy to use, which is applied primarily to reinforced ferroconcrete, metal as well as stone structures. The scale and pace of mass construction increases demand in and puts much pressure on manufacturing (in the factory), cost-effectiveness (both in cost and in material consumption), easiness of transportation and speed of installation at the construction site.

Reduction of labor intensity is of particular importance- both in the manufacture of structures and in the process of erecting buildings and constructions from them. One of the tasks of modern construction is to reduce the weight of the structure due to the widespread use of lightweight effective high-quality materials and to improve structural solutions. One more solutions is the successful and widespread use of modern achievements for the further technical development of construction.

\section{References}

1. V. Kaminsky, O. Georgievsky, B. Budasov, Construction drawing: Textbook. For universities. Under total. Ed.O.V. St. George's, Publishing House "Architecture-S" (2004)

2. I.G. Ovchinnikov, A.I. Likverman, O.N. Rasporov, et al., Corrosion Protection of Metal and Reinforced Concrete Bridge Structures of the Painting Method. Ed. "Kubik", 155, p. 504, Table 23, bib. 175, Saratov (2014)

3. A. Avrenyuk, Restoration of concrete and reinforced concrete structures. LAP Lambert Acad. Publish., p.184 (2011)

4. S. Kudryavtsev, A. Borisova, The research of the freezing and thawing process of the foundations with the use of season and cold-producing devices. MATEC Web of Conf., 193, 20, article number 03040 (2018)

5. T. Danchenko, P. Vede, E. Kiselkin, I. Krasnoukhov, Foundations the foundation of the building. Intern. Scie.-pract. Conf. "Modern science: problems and prospects", pp.17-22 (2017)

6. E. Mityugov, The course of metal structures. Textbook - Moscow: Publishing house of the Association of construction universities (2010) 
7. S. Amelchugov, I. Inzhutov, Thermophysical properties of wood in case of fire in the building: teaching aid . Electronic course, SFU, Krasnoyarsk (2019)

8. E. Rumyantseva, Yu.D. Provincial, Ecological safety of building materials, constructions and products: Textbook. For universities. Under total. ed. HER. ISBN 5-98699-010-2 University Book Publishing House (2005)

9. "Wooden building structures". Electronic resource. Access mode according to the materials of the site: otherreferats.allbest.ru

10. T. Wang, G. Zhou, D. Chao, L. Yin, Influence of hydration heat on stochastic thermal regime of frozen soil foundation considering spatial variability of thermal parameters (Article). Appl. Thermal Eng., 142, pp. 1-9(2018)

11. M. Manaeva, Yu. Nikolenko, In Stone and stone-stone constructions textbook. P.198 (2013)

12. Technology of polymer and polymer-containing building materials and products. Mn .: Belarusian Navuka (2010)

13. M. Berseneva, G. Vasilovskaya, T. Danchenco, et al., Energy-saving technologies in design an cjnstruction of residential buildings and industrial facilities in the far North. Adv. in Intell. Syst. and Comp., 983, pp. 59-68 (2019)

14. Polymer materials - "Plastics as a building material." [Electronic resource]. Access mode based on the materials of the site: polymer branch.com/pull/view/8.html.

15. Siberian Forum 16+, SFU, intellectual dialogue (2019)

16. S. Sychev, D. Shevtsov, Prefabricated high-rise buildings from modular transformed building systems of high factory readiness in the Far North. Bull. of Civ. Eng., 1 (60), pp.153-160 (2019)

17. G. Nekhaev, I. Zakharova, Metal structures in examples and tasks. Book, DIA Publishing House ISBN books: 978-5-93093-716-9 (2010) 